\title{
Serum levels of monocyte chemotactic protein-3/CCL7 are raised in patients with systemic sclerosis: association with extent of skin sclerosis and severity of pulmonary fibrosis
}

\author{
K Yanaba, K Komura, M Kodera, T Matsushita, M Hasegawa, K Takehara, S Sato
}

Ann Rheum Dis 2006;65:124-126. doi: 10.1136/ard.2005.040782

Objective: To determine serum levels of monocyte chemotactic protein-3 (MCP-3) and its clinical associations in patients with systemic sclerosis (SSc).

Methods: Serum MCP-3 levels from 69 patients with SSc were examined by ELISA.

Results: Serum MCP-3 levels were raised in patients with SSc $(n=69)$ compared with healthy controls $(n=28)$. Patients with diffuse cutaneous SSc $(n=36)$ had higher levels of serum MCP-3 than those with limited cutaneous SSc $(n=33)$. Patients with raised MCP-3 levels had pulmonary fibrosis and decreased vital capacity (VC) more often than those with normal MCP-3 levels. MCP-3 levels correlated positively with the extent of skin fibrosis, and inversely with \%VC and carbon monoxide transfer factor (TLCO) in patients with SSc.

Conclusion: MCP-3 levels were increased in patients with $\mathrm{SSc}$, and correlated with the extent of skin sclerosis and the severity of pulmonary fibrosis. These results suggest that MCP-3 may have a role in the development of fibrosis in SSc.

M onocyte chemoattractant proteins (MCPs) of the CC family consist of five proteins termed MCP-1, MCP-2, MCP-3, MCP-4, and MCP-5. Recently, significant abnormalities of MCP-1 expression have been found in systemic sclerosis (SSc). MCP-1 is strongly expressed in the epidermis, perivascular infiltrates, fibroblasts, and keratinocytes, but not expressed in any normal skin. ${ }^{12}$ Furthermore, serum MCP-1 levels are raised in patients with SSc compared with normal controls, and correlate positively with pulmonary fibrosis (PF). Consistently, Luzina et al have reported that MCP-1 levels of protein and mRNA are increased in bronchoalveolar lavage fluids from patients with SSc with alveolitis, compared with patients with SSc without alveolitis, suggesting the potential role of MCP-1 in the development of PF. ${ }^{3}$ These findings suggest that the increased expression of MCP-1 may abnormally recruit leucocytes into the affected tissues of SSc, leading to the development of fibrosis. In this study, we examined serum levels of another MCP chemokine, MCP-3, in patients with SSc, and related these results to clinical features.

\section{PATIENTS AND METHODS \\ Patients}

Serum samples were obtained from 69 Japanese patients with SSc ( 59 female, 10 male). All patients fulfilled criteria for SSc proposed by the American College of Rheumatology. ${ }^{4}$ These patients were grouped according to the classification system proposed by LeRoy et al 53 patients had limited cutaneous SSc (ISSc) and 36 had diffuse cutaneous SSc (dSSc). Anti-topoisomerase I antibodies (Abs) were positive for 41 patients; anticentromere Abs for 21; anti-RNA polymerase Abs for 6. The remaining patient had negative antinuclear Abs. These patients were aged 2-77 years (mean 51 ). Their mean disease duration was 4.2 years (range $0.2-$ 23). Twenty eight healthy Japanese subjects matched for age and sex were used as controls.

\section{Clinical assessment}

Complete medical histories, physical examinations, and laboratory tests were conducted for all patients at their first visit, with evaluations especially for PF during follow up visits. Organ system involvement was defined as described previously ${ }^{6}$ : lung $=$ bibasilar fibrosis on chest radiography and high resolution computed tomography; oesophagus = hypomotility shown by barium radiography; heart = pericarditis, congestive heart failure, or arrhythmias requiring treatment; kidney $=$ malignant hypertension and rapidly progressive renal failure with no other explanation; and muscle $=$ proximal muscle weakness and raised serum creatine kinase. PF was defined as bibasilar interstitial fibrosis on chest high resolution computed tomography. In addition, a pulmonary function test, including vital capacity (VC) and carbon monoxide transfer factor (TLCO), was also evaluated to examine the severity of PF. When the TLCO and VC were $<75 \%$ and $<80 \%$, respectively, of the predicted normal values, they were considered to be abnormal. Patients with SSc who smoked or had respiratory disorders which might have affected the \%TLCo or \%VC, were excluded from this study. The modified Rodnan total skin thickness score (TSS) was measured by summing the skin thickness measurements, and determined by palpation on a $0-3$ scale in 17 body areas. ${ }^{8}$ The protocol was approved by the Kanazawa University Graduate School of Medical Science and Kanazawa University Hospital, and informed consent was obtained from all patients.

\section{Detection of serum MCP-3}

Serum MCP-3 levels were measured with specific enzyme linked immunosorbent assay (ELISA) kits (R\&D Systems, Minneapolis, MN, USA), according to the manufacturer's protocol. This ELISA system can detect all circulating MCP-3 isoforms. Each sample was tested in duplicate. The detection limit of this assay was $1.01 \mathrm{pg} / \mathrm{ml}$.

\section{Statistical analysis}

The Mann-Whitney U test was used to compare MCP-3 levels, Fisher's exact probability test was used to compare frequencies, and Bonferroni's test used for multiple

Abbreviations: Abs, antibodies; dSSc, diffuse cutaneous SSc; ELISA, enzyme linked immunosorbent assay; ISSc, limited cutaneous SSc; MCP, monocyte chemotactic protein; PF, pulmonary fibrosis; SSc, systemic sclerosis; TLCO, carbon monoxide transfer factor; VC, vital capacity 


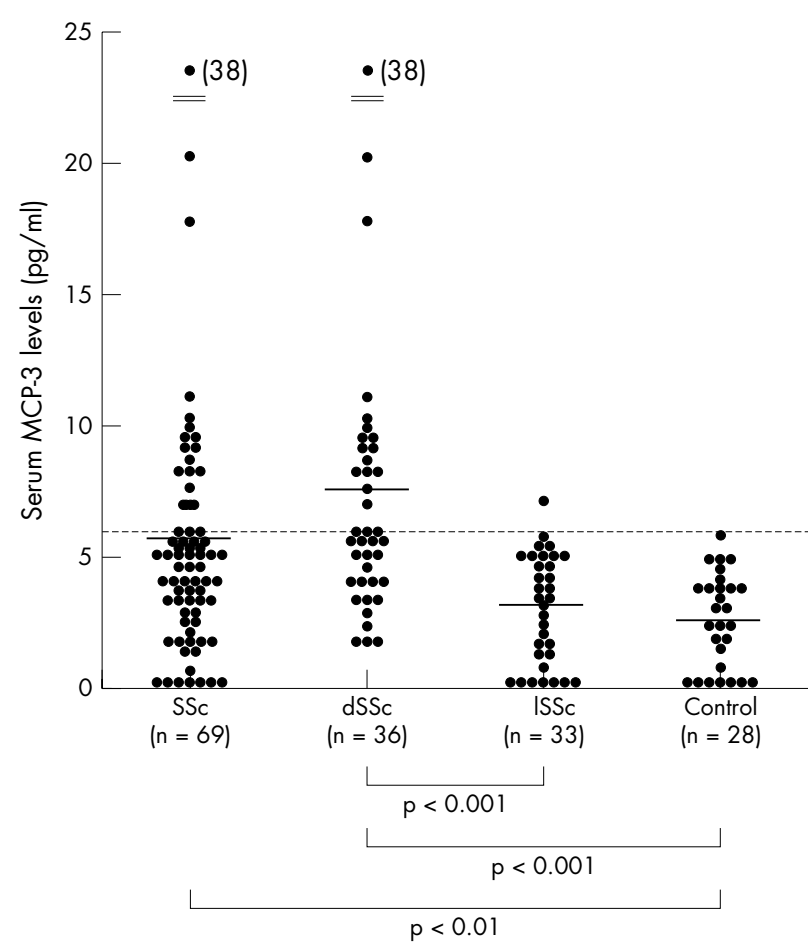

Figure 1 Serum levels of MCP-3 in patients with SSc, dSSc, or ISSc and normal controls (Control). Serum MCP-3 levels were determined by a specific ELISA. Bars indicate the mean value in each group. The broken line indicates the cut off value (mean+2 SD of the normal control samples).

comparisons. Spearman's rank correlation coefficient was used to examine the relationship between two continuous variables. Values of $\mathrm{p}<0.05$ were considered significant.

\section{RESULTS}

\section{Serum MCP-3 levels in SSc}

Figure 1 shows serum levels of MCP-3 in patients with SSC and healthy controls. Serum MCP-3 levels at the first visit were significantly raised in patients with SSc (median $5.3 \mathrm{U} /$ $\mathrm{ml}$, range 0-38.1) compared with healthy controls (2.4, 0-6.2; $\mathrm{p}<0.01)$. For the subgroups of SSc, MCP-3 levels in patients with dSSc $(7.4,2.4-38.1)$ were higher than in those with ISSc $(2.9,0-6.9 ; \mathrm{p}<0.001)$ and healthy controls $(\mathrm{p}<0.001)$. No
Table 1 Clinical and laboratory data in patients with $\mathrm{SSc}$

\begin{tabular}{lll}
\hline Clinical and laboratory data & $\begin{array}{l}\text { Raised MCP-3 } \\
(\mathbf{n}=17)\end{array}$ & $\begin{array}{l}\text { Normal MCP-3 } \\
(\mathbf{n = 5 2})\end{array}$ \\
\hline $\begin{array}{l}\text { Age at onset (years), mean (SD) } \\
\text { Male:female }\end{array}$ & $\begin{array}{l}53(15) \\
4: 13\end{array}$ & $\begin{array}{l}51(17) \\
6: 46\end{array}$ \\
Duration (years), mean (SD) & $2.6(2.4)$ & $4.7(5.1)$ \\
Clinical features & & \\
Contracture of phalanges & 88 & 40 \\
Pitting scars & 47 & 37 \\
Organ involvement & & \\
Lung & $88^{*}$ & 35 \\
Decreased \%VC & $47^{*}$ & 19 \\
$\quad$ Decreased \%TLCO & 76 & 52 \\
Oesophagus & 71 & 65 \\
Heart & 24 & 15 \\
Muscle & 12 & 17 \\
Laboratory findings & & \\
Anti-topoisomerase I antibody & $82^{*}$ & 38 \\
Anticentromere antibody & $6^{*}$ & 54 \\
Increased lgG & 41 & 23 \\
Raised ESR & 35 & 23 \\
Raised CRP & 0 & 15 \\
\hline
\end{tabular}

Results are shown as percentages.

VC, vital capacity; TLCO, carbon monoxide transfer factor; ESR, erythrocyte sedimentation rate; CRP, $C$ reactive protein. ${ }^{*} \mathrm{p}<0.05$, versus patients with SSc with normal MCP-3 levels.

significant difference in serum MCP-3 levels was seen between patients with 1SSc and healthy controls.

\section{Clinical correlation of serum MCP-3 levels}

Values higher than the mean+2 SD $(5.96 \mathrm{U} / \mathrm{ml})$ of the control serum samples were considered to be raised in this study. Raised MCP-3 levels were seen in 17/69 (25\%) of all patients with SSc, in 16/36 (44\%) patients with dSSc, and in 1/33 (3\%) patients with ISSc. Consistent with the association of raised MCP-3 levels with dSSc, patients with SSc with raised MCP-3 levels had anti-topoisomerase I Abs more frequently, but had anticentromere Abs less frequently than those with normal MCP-3 levels $(p<0.05$; table 1$)$. In addition, MCP-3 levels correlated positively with the modified Rodnan TSS $\left(r_{\mathrm{s}}=0.35, \mathrm{p}<0.01\right.$; fig 2$)$. The prevalence of PF and decreased $\% \mathrm{VC}$ in patients with SSc with raised MCP-3 levels was significantly higher than in those with normal MCP-3 levels (88\% v 35\%, p $<0.05$ and 47\% v 19\%, p <0.05, respectively; table 1). Furthermore, MCP-3 levels correlated inversely with $\% \mathrm{VC}$ and \%TLCO in patients with SSc $\left(r_{\mathrm{s}}=-0.41, \mathrm{p}<0.001\right.$ and $r_{\mathrm{s}}=-0.35, \mathrm{p}<0.01$, respectively; fig 2 ). Thus, MCP-3
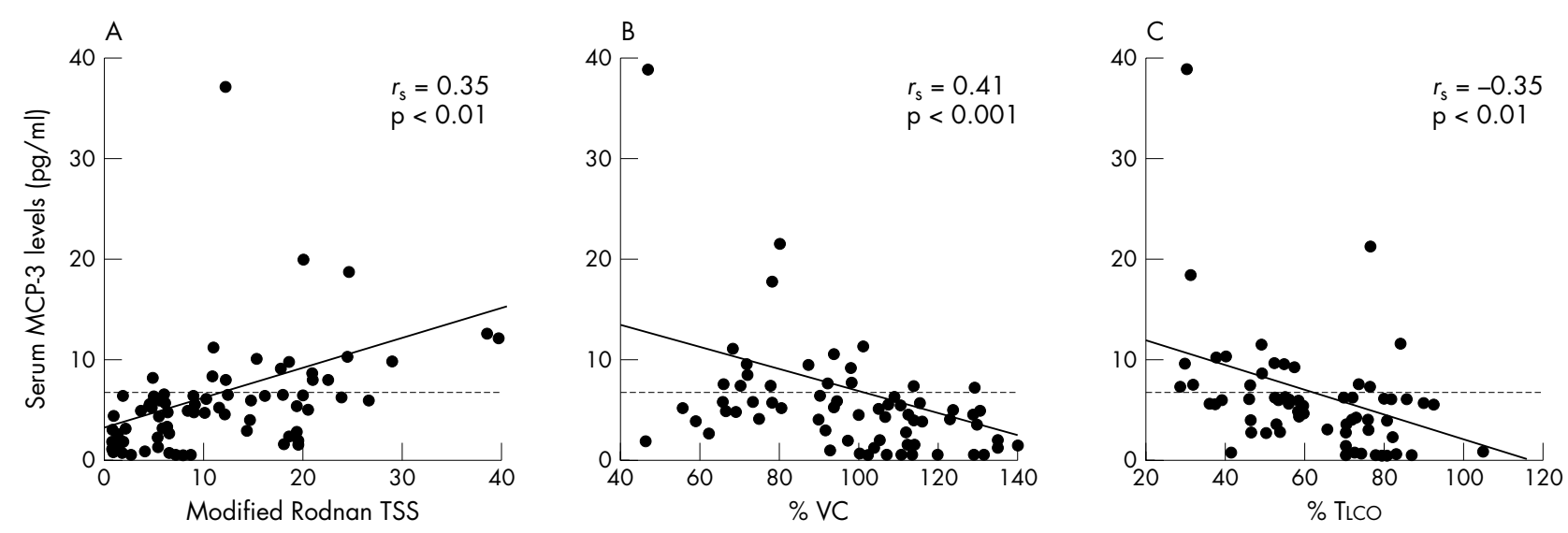

Figure 2 The correlation of MCP-3 levels with modified Rodnan total skin thickness score (TSS) (A); \%VC (B); and \%TLCO (C) in patients with SSc. Serum MCP-3 levels were determined with a specific ELISA. The broken lines indicate the cut off value. 
levels correlated not only with the extent of skin sclerosis but also with the severity of PF in SSc.

\section{DISCUSSION}

MCP-3 is a powerful chemotactic protein that elicits the infiltration of monocytes, activated T lymphocytes, eosinophils, and basophils. ${ }^{10}$ Interestingly, a recent study has shown that infiltrating monocytes around blood vessels strongly express MCP-3 in the skin of patients with early stage dSSc, whereas it is not seen in the skin of patients with late stage dSSc or 1SSc. ${ }^{11}$ Histological analysis of the initial stage of SSc shows the presence of perivascular infiltrates of mononuclear cells in the dermis, which is associated with increased collagen synthesis in the surrounding fibroblasts. ${ }^{12}$ Consistently, our study showed that patients with dSSc had increasing MCP-3 levels. Collectively, these observations suggest that the augmented expression of MCP-3 abnormally recruits monocytes into the skin of SSc, mediating the initiation and progression of skin sclerosis.

In this study, serum MCP-3 levels correlated significantly with the presence and severity of PF. Although few studies have analysed the significance of MCP-3 in patients with PF, lung MCP-3 expression is augmented in murine bleomycin induced and radiation induced PF. ${ }^{13}{ }^{14}$ Furthermore, on lung biopsy specimens from patients with SSc with PF, macrophages accumulate in the interstitium, with total increased number of macrophages in bronchoalveolar lavage fluid. ${ }^{15}$ Therefore, the abnormal accumulation of macrophages in the lungs may result from augmented local production of MCP-3 in the affected lungs of SSc, leading to raised serum MCP-3 levels in patients with SSc.

In our study, serum MCP-3 levels appeared to correlate with the disease severity of SSc, suggesting that MCP-3 plays a part in the disease process, possibly by augmenting leucocyte migration in the affected tissues in SSc. At present, no appropriate treatment for skin sclerosis and PF in SSc has been established. Therefore, these findings suggest that MCP3 might be a therapeutic target in patients with SSc who have severe skin sclerosis or PF.

\section{Authors' affiliations}

K Yanaba, K Komura, M Kodera, T Matsushita, M Hasegawa, K Takehara, Department of Dermatology, Kanazawa University Graduate School of Medical Science, Kanazawa, Japan

S Sato, Department of Dermatology, Nagasaki University Graduate School of Biomedical Science, Nagasaki, Japan
Correspondence to: Dr S Sato, Department of Dermatology, Nagasaki University Graduate School of Biomedical Science, 1-7-1 Sakamoto, Nagasaki, 852-8501, Japan; s-sato@net.nagasaki-u.ac.jp

Accepted 15 May 2005

\section{REFERENCES}

1 Hasegawa $M$, Sato S, Takehara K. Augmented production of chemokines (MCP-1, MIP-1a, and MIP-1b) in patients with systemic sclerosis: MCP-1 and MIP-la may be involved in the development of pulmonary fibrosis. Clin Exp Immunol 1999; 117:159-65

2 Distler O, Pap T, Kowal-Bielecka O, Meyringer R, Guiducci S, Landthaler M, et al. Overexpression of monocyte chemoattractant protein 1 in systemic sclerosis: role of platelet-derived growth factor and effects on monocyte chemotaxis and collagen synthesis. Arthritis Rheum 2001;44:2665-78.

3 Luzina IG, Atamas SP, Wise R, Wigley FM, Xiao HQ, White B. Gene expression in bronchoalveolar lavage cells from scleroderma patients. Am J Respir Cell Mol Biol 2002;26:549-57.

4 ARA. Subcommittee for Scleroderma Criteria of the American Rheumatism Association Diagnostic and Therapeutic Criteria Committee: Preliminary criteria for the classification of systemic sclerosis (scleroderma). Arthritis Rheum 1980;23:581-90.

5 LeRoy EC, Krieg T, Black C, Medsger TAJ, Fleischmajer R, Rowell N, et al. Scleroderma (systemic sclerosis): classification, subsets, and pathogenesis. J Rheumatol 1988;15:202-5.

6 Steen VD, Powell DL, Medsger TAJ. Clinical correlations and prognosis based on serum autoantibodies in patients with systemic sclerosis. Arthritis Rheum 1988;31:196-203.

7 Sato S, Ihn H, Kikuchi K, Takehara K. Antihistone antibodies in systemic sclerosis: association with pulmonary fibrosis. Arthritis Rheum 1994; 37:391-4.

8 Clements PJ, Lachenbruch PA, Seibold JR, Zee B, Steen VD, Brennan P, et al. Skin thickness score in systemic sclerosis: an assessment of interobserver variability in 3 independent studies. J Rheumatol 1993;20:1892-6.

9 Van Damme J, Proost P, Lenaerts JP, Opdenakker G. Structural and functional identification of two human, tumor-derived monocyte chemotactic proteins (MCP-2 and MCP-3) belonging to the chemokine family. J Exp Med 1992; 176:59-65.

10 Dahinden CA, Geiser T, Brunner T, von Tscharner V, Caput D, Ferrara P, et al. Monocyte chemotactic protein 3 is a most effective basophil- and eosinophilactivating chemokine. J Exp Med 1994;179:751-6.

11 Ong VH, Evans LA, Shiwen X, Fisher IB, Rajkumar V, Abraham DJ, et al. Monocyte chemoattractant protein 3 as a mediator of fibrosis: overexpression in systemic sclerosis and the type 1 tight-skin mouse. Arthritis Rheum 2003;48:1979-91.

12 Scharffetter K, Lankat-Buttgereit B, Krieg T. Localization of collagen mRNA in normal and scleroderma skin by in-situ hybridization. Eur J Clin Invest 1988;18:9-17.

13 Kaminski N, Allard JD, Pittet JF, Zuo F, Griffiths MJ, Morris D, et al. Global analysis of gene expression in pulmonary fibrosis reveals distinct programs regulating lung inflammation and fibrosis. Proc Natl Acad Sci USA 2000;97:1778-83.

14 Johnston CJ, Williams JP, Okunieff P, Finkelstein JN. Radiation-induced pulmonary fibrosis: examination of chemokine and chemokine receptor families. Radiat Res 2002;157:256-65.

15 Silver RM, Miller KS, Kinsella MB, Smith EA, Schabel SI. Evaluation and management of scleroderma lung disease using bronchoalveolar lavage. Am J Med 1990;88:470-6. 